\title{
The power of stress echocardiography and myocardial perfusion scintigraphy in predicting long-term outcome. Nothing lasts forever
}

\author{
Abdou Elhendy, MD, PhD ${ }^{a}$ \\ a Department of Cardiology, Marshfield Clinic, Marshfield, WI
}

Received Jul 12, 2016; accepted Jul 13, 2016

doi: 10.1007/s12350-016-0621-1

\section{See related article, pp. 471-479}

Cardiac stress imaging with either echocardiography or myocardial perfusion scintigraphy is a wellestablished method for evaluation of coronary artery disease and predicting outcome. ${ }^{1-4}$ In the current issue of the journal, Boiten et al reported the longest-term follow-up after stress imaging in 301 patients who underwent dobutamine stress test with simultaneous echocardiography and sestamibi myocardial perfusion SPECT imaging (MPI). Patients were followed for an average of 14 years. An abnormal test was strongly predictive of adverse outcome. ${ }^{5}$ Both stress echocardiography and MPI were comparable in predicting mortality and hard cardiac events. Although the number of patients was relatively small particularly during the later phase of the follow-up, the study has shown clearly a sustained prognostic value of both techniques with separation of survival curves in those with normal versus abnormal study for at least 10-12 years after the test.

Based on these results, some important questions arise. Do we know everything after the stress test? Is there a need to repeat the stress test or do a different kind of imaging? The answer is probably yes in some patients, but who are these and why? What kind of subsequent imaging modality should we consider?

Reprint requests: Abdou Elhendy, MD, PhD, Department of cardiology, Marshfield Clinic, Marshfield, WI; elhendy.abdou@ marshfieldclinic.org

J Nucl Cardiol 2018;25:480-2.

$1071-3581 / \$ 34.00$

Copyright (C) 2016 American Society of Nuclear Cardiology.

\section{ORDERING ANOTHER TEST AFTER A NORMAL STUDY}

Events after a normal test will depend on the screened population and their life-long risk of developing significant cardiovascular disease. The initial stress test will likely be normal in those with normal coronary arteries as well as those with mild to moderate disease. If the population consisted initially of the latter group, it is likely that cardiac events will occur during longer-term follow-up due to progression of the disease that was not severe enough to cause abnormalities on earlier functional imaging; hence continued surveillance in individuals with higher clinical risk profile is warranted. ${ }^{6}$ The recent development in hybrid imaging has particularly been useful in this situation. A low-dose CT used for attenuation correction applied with myocardial perfusion SPECT imaging in state-of-the-art laboratories can identify patients with a normal perfusion who may otherwise still be at high risk of cardiac events over the longer term in association with significant coronary artery calcifications. In some occasions, very severe coronary artery calcifications can be a red flag that the test is false negative due to severe diffuse coronary artery disease and balanced hypoperfusion. ${ }^{7,8}$

Various clinical and stress test variables have been associated with the occurrence of cardiac events despite a normal stress imaging study. These include diabetes mellitus, advanced age, inability to perform exercise stress test, and prior history of coronary artery disease..$^{9-11}$ One study showed that after a normal dobutamine stress echocardiogram, the annual hard cardiac event rate was $0.8 \%$ in the first 3 years and $1.7 \%$ between the fourth and sixth years, suggesting a potential need to repeat the test after the third year. ${ }^{10}$ In a study of patients with normal stress MPI who had previous myocardial infarction and/or revascularization, annual cardiac death rates were $0.5 \%$ during the first 3 years of follow-up and $1.3 \%$ in the subsequent 3 years. ${ }^{11}$ 


\section{REPEATING THE STRESS TEST AFTER AN ABNORMAL STUDY}

When patients subsequently receive revascularization, appropriateness criteria have been established for stress testing thereafter. ${ }^{1}$ In most prognostic studies, these patients are censored if revascularization had occurred within 3 months following the stress test. Still a significant number of patients may not receive revascularization after abnormal stress test. The list of reasons include, patient/physician preferences for medical management, the absence of symptoms, high risk of intervention, small size of abnormalities, false-positive results, and unsuitable anatomy for revascularization. Another common reason for not considering revascularization is the presence of fixed defect without ischemia as was the case in many patients included in the current study. Interestingly, a previous study has shown that among patients with no history of previous infarction, fixed perfusion abnormalities were associated with more adverse outcome compared to reversible abnormalities. ${ }^{12}$

Repeating the stress test in some patients who had an earlier positive study may be clinically useful to assess improvement with medical therapy and reevaluate the area at risk. The findings of this study of continued diversion of survival curves during the long-term followup among patients with abnormal stress test make the case for the need to repeat the test particularly in patients with initially mild to moderate abnormality as these patients appear to be at continued risk of cardiac events. The follow-up stress test may detect further increase in the severity and extent of functional abnormalities, ${ }^{6}$ lower ischemic threshold, worsening of left ventricular function, adverse cardiac remodeling, and peri-infarct or remote ischemia in patients with predominantly fixed defects on initial study. These abnormalities may herald a status of higher risk than initially anticipated and may guide the physician in deciding to proceed with revascularization and or intensify medical therapy.

\section{ALL-CAUSE MORTALITY}

One unique finding of this study is that $57 \%$ of patients died during this long-term follow-up yielding roughly a $4 \%$ or more annual mortality rate. Although death was considered cardiac in $42 \%$ of cases, survival curves continued to separate in patients with normal versus abnormal stress test for at least 12 years following the stress test. Apart from the known limitations of determining the cause of death, ${ }^{13}$ the association of abnormal stress test with noncardiac mortality may be related to the association of coronary artery disease with other risk factors and clinical diagnoses that may lead to death such as diabetes mellitus, hypertension, stroke, renal failure, and peripheral vascular disease. Therefore it can be speculated that aggressive risk factor modification could potentially reduce what is usually classified as noncardiac mortality as well. The results of the stress test could guide as how aggressive risk factor management should be implemented.

\section{THE RISK AFTER AN ABNORMAL STRESS TEST MAY BE UNDERESTIMATED}

Early revascularization after stress testing is usually performed in patients with the most severe disease based on stress test/angiographic results. Exclusion of these patients does very likely reduce positive predictive value of abnormal stress test by eliminating true-positive studies. Similarly, patients with a positive test who have late revascularization may enjoy better outcome. This may artificially lower the calculated odds of cardiac events after a positive study. These limitations are inherent to all prognostic studies as it is mandated to perform revascularization when clinical need is obvious. Other factors that may lead to underestimation of the risk after a positive stress test include attenuation of the extent of ischemia by factors such as cardiac medications, suboptimal stress, and the presence of artifacts or poor endocardial resolution.

\section{THE NEW TECHNOLOGY}

Application of attenuation correction and implementing gated studies with observation of transient ischemic dilation may further improve prognostic accuracy of stress MPI beyond what is reported in this study. Additionally, the use of hybrid imaging can be very useful by identifying patients with significant coronary artery calcifications. ${ }^{7,8}$ This observation could set the requirement for closer follow-up after a normal MPI and may drive suspicion that ischemia may have been underestimated in those with severe calcification who have otherwise a small perfusion defect. This advantage is obviously not attainable by stress echocardiography. The recent introduction of combined vasodilator and exercise MPI is an added advantage of radionuclide imaging in patients who can only perform a limited exercise test. On the other side, the use of myocardial contrast agents with stress echocardiography to improve endocardial border delineation and to assess perfusion may further improve the prognostic accuracy of stress echocardiography. ${ }^{14-16}$

\section{SUMMARY}

The results of the current study show that the findings of stress echocardiography and MPI remain predictive of cardiac events and mortality during a very 
long-term follow-up. These results are very useful and guide the physicians regarding short- and longer-term patient's management. Follow-up plans should be individualized based on patients' clinical risk profile and potential limitations of the stress test should be sought off. With the occurrence of more events during longerterm follow-up, the positive predictive value of these imaging modalities increase, but obviously with increasing cumulative events in patients with normal study, the negative predictive value drops. Therefore, considerations to repeat the test at intermediate follow-up should be made. Although some studies suggested that the test should be preferably repeated after 3 years, the need and the exact timing of repeating the test remains to be determined. The overall mortality in this 14 -year followup study was staggering $57 \%$ and $30-40 \%$ of patients with normal stress test died during that period. Therefore, we should not always hang on the results of one test for infinite assessment of prognosis as nothing lasts forever.

\section{References}

1. ACCF/ASNC/ACR/AHA/ASE/SCCT/SCMR/SNM 2009 Appropriate Use Criteria for Cardiac Radionuclide Imaging: A Report of the American College of Cardiology Foundation Appropriate Use Criteria Task Force, the American Society of Nuclear Cardiology, the American College of Radiology, the American Heart Association, the American Society of Echocardiography, the Society of Cardiovascular Computed Tomography, the Society for Cardiovascular Magnetic Resonance, and the Society of Nuclear Medicine. Hendel RC, Berman DS, Di Carli MF, Heidenreich PA, Henkin RE, Pellikka PA, Pohost GM, Williams KA; American College of Cardiology Foundation Appropriate Use Criteria Task Force; American Society of Nuclear Cardiology; American College of Radiology; American Heart Association; American Society of Echocardiology; Society of Cardiovascular Computed Tomography; Society for Cardiovascular Magnetic Resonance; Society of Nuclear Medicine. 2009:53:2201-29.

2. Pellikka PA, Nagueh SF, Elhendy AA, Kuehl CA, Sawada SG, American Society of Echocardiography. American Society of Echocardiography recommendations for performance, interpretation, and application of stress echocardiography. J Am Soc Echocardiogr. 2007;20:1021-41.

3. Hachamovitch R, Berman DS, Shaw LJ, Kiat H, Cohen I, Cabico JA, Friedman J, Diamond GA. Incremental prognostic value of myocardial perfusion single photon emission computed tomography for the prediction of cardiac death: differential stratification for risk of cardiac death and myocardial infarction. Circulation 1998;97:535-43. Erratum in: Circulation 1998;98:190.

4. Shaw LJ, Iskandrian AE. Prognostic value of gated myocardial perfusion SPECT. J Nucl Cardiol 2004;11:171-85. Review.

5. Boiten HJ, van Domburg RT, Geleijnse ML, Valkema R, Zijlstra F, Schinkel AFL. Cardiac stress imaging for the prediction of very long-term outcomes: dobutamine stress echocardiography or dobutamine ${ }^{99 \mathrm{~m}} \mathrm{Tc}$-sestamibi SPECT? J Nucl Cardiol. doi:10. 1007/s12350-016-0521-4.

6. Iskandrian AE, Roth $\mathrm{CP}$, Hage FG. Serial imaging and outcome prediction. J Nucl Cardiol. 2016;23:117-21.

7. Rana JS, Rozanski A, Berman DS. Combination of myocardial perfusion imaging and coronary artery calcium scanning: Potential synergies for improving risk assessment in subjects with suspected coronary artery disease. Curr Atheroscler Rep. 2011;13:381-9.

8. Patchett ND, Pawar S, Miller EJ. Visual identification of coronary calcifications on attenuation correction $\mathrm{CT}$ improves diagnostic accuracy of SPECT/CT myocardial perfusion imaging. J Nucl Cardiol 2016 Feb 5. [Epub ahead of print].

9. Chaowalit N, McCully RB, Callahan MJ, Mookadam F, Bailey KR, Pellikka PA. Outcomes after normal dobutamine stress echocardiography and predictors of adverse events: Long-term follow-up of 3014 patients. Eur Heart J. 2006;27:3039-44.

10. Sozzi FB, Elhendy A, Roelandt JR, van Domburg RT, Schinkel AF, Vourvouri EC, Bax JJ, Rizzello V, Poldermans D. Long-term prognosis after normal dobutamine stress echocardiography. Am J Cardiol. 2003;92:1267-70.

11. Schinkel AF, Elhendy A, Bax JJ, van Domburg RT, Huurman A, Valkema R, Biagini E, Rizzello V, Feringa HH, Krenning EP, Simoons ML, Poldermans D. Prognostic implications of a normal stress technetium-99m-tetrofosmin myocardial perfusion study in patients with a healed myocardial infarct and/or previous coronary revascularization. Am J Cardiol. 2006;97:1-6.

12. Elhendy A, Schinkel AF, van Domburg RT, Bax JJ, Poldermans D. Prognostic significance of fixed perfusion abnormalities on stress technetium-99m sestamibi single-photon emission computed tomography in patients without known coronary artery disease. Am J Cardiol. 2003;92:1165-70.

13. Gottlieb SS. Dead is dead-Artificial definitions are no substitute. Lancet. 1997;349:662-3.

14. Tweet MS, Arruda-Olson AM, Anavekar NS, Pellikka PA. Stress echocardiography: What is new and how does it compare with myocardial perfusion imaging and other modalities? Curr Cardiol Rep. 2015;17:43.

15. Elhendy A, Porter TR. Assessment of myocardial perfusion with real-time myocardial contrast echocardiography: Methodology and clinical applications. J Nucl Cardiol 2005;12:582-90. Review.

16. Tsutsui JM, Elhendy A, Anderson JR, Xie F, McGrain AC, Porter TR. Prognostic value of dobutamine stress myocardial contrast perfusion echocardiography. Circulation. 2005;6:1444-50. 